\title{
DIABETES, OBESITY AND METABOLISM
}

\section{A JOURNAL OF PHARMACOLOGY AND THERAPEUTICS}

This is the peer reviewed version of the following article: Al-Qaissi A, Papageorgiou M, Javed Z, et al. Environmental effects of ambient temperature and relative humidity on insulin pharmacodynamics in adults with type 1 diabetes mellitus. Diabetes Obes Metab. 2019;21:569-574, which has been published in final form at https://doi.org/10.1111/dom.13555. This article may be used for non-commercial purposes in accordance with Wiley Terms and Conditions for Use of Self-Archived Versions.

\section{Environmental effects of ambient temperature and relative humidity on insulin pharmacodynamics in adults with type 1 diabetes mellitus}

\begin{tabular}{|c|c|}
\hline Journal: & Diabetes, Obesity and Metabolism \\
\hline Manuscript ID & DOM-18-0857-OP.R1 \\
\hline Manuscript Type: & Original Paper \\
\hline Date Submitted by the Author: & 20-Sep-2018 \\
\hline Complete List of Authors: & $\begin{array}{l}\text { Al-Qaissi, Ahmed; Hull Royal Infirmary, Department of Academic Diabetes, } \\
\text { Endocrinology and Metabolism } \\
\text { Papageorgiou, Maria; Hull Royal Infirmary, Department of Academic } \\
\text { Diabetes, Endocrinology and Metabolism } \\
\text { Javed, Zeeshan; Pakistan Kidney and Liver Institute and Research Center, } \\
\text { Department of Endocrinology and Diabetes } \\
\text { Heise, Tim; Profil Institut für Stoffwechselforschung GmbH, } \\
\text { Rigby, Alan; Hull York Medical School, University of Hull } \\
\text { Garrett, Andrew; University of Hull, Department of Sport, Health and } \\
\text { Exercise Science } \\
\text { Hepburn, David; Hull and East Yorkshire Hospitals NHS Trust and Hull York } \\
\text { Medical School, Department of Academic Diabetes, Endocrinology and } \\
\text { Metabolism } \\
\text { Kilpatrick, Eric; Sidra Medical and Research Center } \\
\text { Atkin, Stephen; Weil Cornell Medical College, Diabetes, Endocrinology and } \\
\text { Metabolism } \\
\text { Sathyapalan, Thozhukat; Hull York Medical School, Department of } \\
\text { Academic Diabetes, Endocrinology and Metabolism }\end{array}$ \\
\hline Key Words: & type 1 diabetes, insulin analogues, pharmacodynamics \\
\hline
\end{tabular}




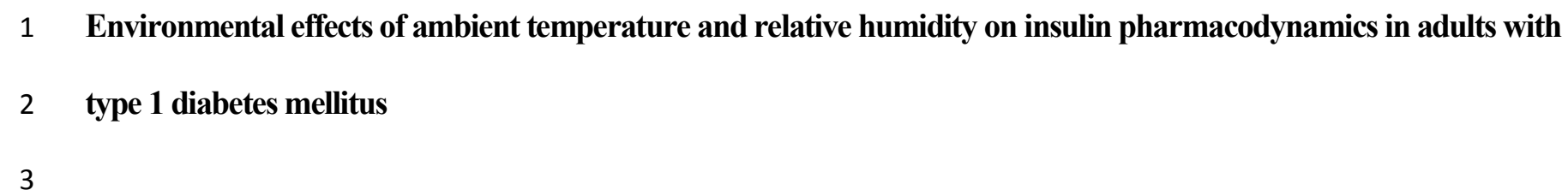

$9 \quad{ }^{1}$ Department of Academic Diabetes, Endocrinology and Metabolism, Hull York Medical School, University of 10 Hull, Hull,UK; ahmedsattar1978@yahoo.com (A.A); M.Papageorgiou@hull.ac.uk (M.P.);

11 zeeshan.javed@pkli.org.pk (Z.J.); Thozhukat.Sathyapalan@hyms.ac.uk (T.S.)

$12{ }^{2}$ Pakistan Kidney and Liver Institute and Research Center, DHA Phase 6, Lahore, Pakistan;

13 Zeeshan.Javed@pkli.org.pk (Z.J.)

$14{ }^{3}$ Profil, Neuss, Germany; Tim.Heise@profil.com (T.H.)

${ }^{4}$ Department of Academic Cardiology, Hull York Medical School, University of Hull, Hull, UK;

$16 \quad$ A.rigby@,hull.ac.uk (A.R.)

$17{ }^{5}$ Department of Sport, Health and Exercise Science, University of Hull, Hull, UK; $\underline{\text { A.Garrett@hull.ac.uk }}$

18 (A.T.G.)

$19{ }^{6}$ Department of Academic Diabetes, Endocrinology and Metabolism, Hull and East Yorkshire Hospitals NHS

20 Trust and Hull York Medical School, University of Hull, UK; David.Hepburn@hull.ac.uk

$21 \quad{ }^{7}$ Department of Pathology, Sidra Medicine, Doha, Qatar; ekilpatrick@,sidra.org (E.S.K.)

$22{ }^{8}$ Weill Cornell Medicine in Qatar, Education City, P.O. Box 24144, Qatar; Sla2002@qatar-med.cornell.edu

23 (S.L.A.) 
24 Correspondence: Professor Thozhukat Sathyapalan, Department of Academic Diabetes, Endocrinology and

25 Metabolism, Hull Medical School, University of Hull, Hull, UK, Email address: Thozhukat.Sathyapalan@hyms.ac.uk. 


\section{Abstract}

27 Objective: This study aimed to explore the effects of ambient temperature and relative humidity on insulin 28 pharmacodynamics in adults with type 1 diabetes.

29 Research Design: A 3-way, cross-over, randomised study was performed in adults with type 1 diabetes 30 mellitus $(n=10)$. The pharmacodynamics profile of a single dose of short-acting insulin (insulin lispro) was 31 investigated under three environmental conditions: i) temperature: $15^{\circ} \mathrm{C}$ and humidity: $10 \%$, ii) temperature: $3230^{\circ} \mathrm{C}$ and humidity: $10 \%$, and iii) temperature: $30^{\circ} \mathrm{C}$ and humidity: $60 \%$, controlled in an environmental 33 chamber. Euglycaemic glucose clamp technique ensured a constant blood glucose of $100 \mathrm{mg} / \mathrm{dl}(5.5 \mathrm{mmol} / \mathrm{l})$.

34 The following pharmacodynamic endpoints were calculated: maximum glucose infusion rate (GIR $\max _{\max }$, time to $35 \mathrm{GIR}_{\max }\left(\mathrm{t}_{\mathrm{GIRmax}}\right)$, total area under the curve (AUC) for GIR from 0-6 hours (AUC $\mathrm{GIR} .0-6 \mathrm{~h}$ ), and partial AUCs $36\left(\mathrm{AUC}_{\mathrm{GIR} .0-1 \mathrm{~h}}, \mathrm{AUC}_{\mathrm{GIR} .0-2 \mathrm{~h}}\right.$ and $\left.\mathrm{AUC}_{\mathrm{GIR} .2-6 \mathrm{~h}}\right)$.

37 Results: Higher temperature $\left(30^{\circ} \mathrm{C}\right)$ under $10 \%$ fixed humidity resulted in a greater $\operatorname{GIR}_{\max }(p=0.04)$, a later $38 \mathrm{t}_{\mathrm{GIR} . \max }(p=0.049)$ compared to lower temperature $\left(15^{\circ} \mathrm{C}\right)$. Humidity did not affect any pharmacodynamic 39 parameter. When the combined effects of temperature and humidity were explored, $\mathrm{t}_{\mathrm{GIR} \cdot \max }(p=0.008)$ occurred 40 earlier with a lower late insulin pharmacodynamic effect $\left(\mathrm{AUC}_{\mathrm{GIR} .2-6 \mathrm{~h},} p=0.017\right)$ at temperature $15^{\circ} \mathrm{C}$ and 41 humidity $10 \%$ compared to temperature $30^{\circ} \mathrm{C}$ and humidity $60 \%$.

42 Conclusions: High ambient temperature resulted in greater insulin peak effect compared to low ambient 43 temperature, with the contribution of high relative humidity only apparent at high ambient temperature. This 44 suggests that patients with type 1 diabetes mellitus entering higher environmental temperatures with or without 45 high humidity could experience more hypoglycaemic events. 
50

51

5

5 10

\section{Introduction}

51 Type 1 diabetes mellitus is characterised by $\beta$-cell destruction and a lifelong requirement of exogenous insulin. Insulin requirements depend on insulin absorption from the injection site, the individual's insulin sensitivity, body composition, inflammatory processes and environmental factors $(1,2)$. Evidence from epidemiological research suggests seasonal differences in HbAlc (3-5) and clinical onset of diabetes (6), with warmer temperature (summer) favouring lower $\mathrm{HbAlc}$ and lower incidence of diabetes compared to cooler temperatures (winter). Conversely, there is paucity of recent, well-controlled experimental studies employing technological advancements, such as an environmental chamber (7) using the gold standard glucose clamp technique (8) to investigate the effects of ambient temperature on insulin action, which could provide evidence of a cause-effect relationship. Nevertheless, there is increasing evidence of the local effects of temperature on insulin pharmacodynamics and pharmacokinetics. For instance, local warming of the injection site as a result of local skin massage (9), application of an insulin infusion site heating device (InsuPatch $\left.{ }^{\mathrm{TM}}\right)(10-13)$, hot baths

62 (14), or sauna exposure (15) has been shown to accelerate insulin absorption and improve insulin sensitivity in patients with diabetes, with these effects largely mediated by an increase in skin temperature, which results in an increased perfusion at the injection site.

65 The effects of relative humidity on insulin pharmacodynamics and pharmacokinetics are largely unexplored. An epidemiological study conducted in the Mediterranean area suggested an increased prevalence of diabetes among the elderly who lived in islands with high relative environmental humidity when adjusted for ambient temperature (16). Notably, high relative humidity often occurs in the presence of high ambient temperature, making it challenging to unravel their individual effects (17). Individuals with diabetes appear to tolerate moist, warm air above $50 \%$ humidity less well than adults without diabetes (18). This may be due to the fact that high humidity when combined with high temperature decreases the rate of cooling of the human body leading to tiredness, exhaustion, reduction in alertness and potentially heat stroke $(17,19,20)$, which may also affect glycaemic control.

74 In order to assess the independent and combined effects of ambient temperature and relative humidity, this 75 study evaluated the insulin pharmacodynamic profile following a single injection of a short-acting insulin analogue. 


\section{$77 \quad$ Research Design and Methods}

78 A single-centre, open label, 3-way cross-over study was performed in the Diabetes Research Centre at Hull 79 Royal Infirmary in adults with type 1 diabetes mellitus $(n=10)$. All participants provided their written informed 80 consent. The trial was approved by the Yorkshire \& the Humber - Leeds West Research Ethics Committee

3

列

88

4

5
and adverts placed in the Diabetes Centre at the Hull Royal Infirmary. Participants were included if they i) were males, ii) aged between 18-55 years, iii) had been diagnosed with type 1 diabetes mellitus, iv) had HbA1c $\leq 9.0$ $\%(75 \mathrm{mmol} / \mathrm{mol})$ and a total insulin dose of $<1.2 \mathrm{U} / \mathrm{kg} / \mathrm{day}$, and $\mathrm{v})$ had a body mass index (BMI) between 18.0 and $28.0 \mathrm{~kg} / \mathrm{m}^{2}$. Exclusion criteria were: i) known or suspected allergy to insulin, ii) recurrent major hypoglycaemia or hypoglycaemic unawareness within the previous 6 months, iii) clinically significant diabetes neuropathy, iv) participation in clinical trials involving investigational drugs within 3 months prior to screening and v) supine blood pressure at screening outside the range of $90-140 \mathrm{mmHg}$ for systolic blood pressure or 50$90 \mathrm{mmHg}$ for diastolic blood pressure and/or resting supine heart rate outside the range 50 -90 beats per minute.

The pharmacodynamic profile of the short-acting insulin lispro dosed at 0.2 units $/ \mathrm{kg}$ was investigated under three environmental conditions for each subject: i) temperature: $15^{\circ} \mathrm{C}$ and humidity: $10 \%$, ii) temperature: $30^{\circ} \mathrm{C}$ and humidity: $10 \%$, and iii) temperature: $30^{\circ} \mathrm{C}$ and humidity: $60 \%$. Participants attended six visits (Visits 1 , 2a, 2b, 3, 4 and 5). Visit 1, 2a and 5 were conducted in the Diabetes Centre, Hull Royal Infirmary, whereas Visits 2b-4 were performed at the environmental chamber (Type SSR 60-20H, Design and Manufacture of Environmental Test Chambers, Gwent, Wales) located at the Department of Sport, Health \& Exercise, University of Hull. During Visit 1, potential participants were screened against inclusion and exclusion criteria by medical history and clinical examination, routine blood tests (i.e., HbA1c) and an electrocardiogram (ECG). Visit $2 \mathrm{a}$ was performed $>72$ hours prior to Visit $2 \mathrm{~b}$ to discuss and allow any arrangements in insulin regimens and lifestyle (diet, exercise). More specifically, participants were switched from insulin Lantus or Detemir to neutral protamine hagedorn (NPH) insulin 48 hours before Visit 2b. The NPH insulin was stopped 22 hours before Visit 2b-4, except for short acting insulin analogues, which were stopped 6-8 hours before that visit. Visits 2b-4 were the main experimental days, during which different environmental conditions were controlled 
04 and the euglycaemic clamp was performed. Participants were weighed without shoes on a weighing scale 05 (Marsden Weighing Machine Group Ltd, UK), height was taken barefoot using a wall-mounted stadiometer and 06 BMI was calculated as body mass $(\mathrm{kg})$ divided by the height squared $\left(\mathrm{m}^{2}\right)$. Blood pressure was measured using 07 a sphygmomanometer (Datascope Duo Masimo Set, Mindray Ltd, UK). Blood glucose was continuously 10

\section{Euglycaemic glucose clamp procedure}

Prior to the euglycaemic glucose clamp, all participants fasted overnight and for the duration of the 6-hour procedure. Water was allowed as required. In the clinic room, with the participant in a comfortable supine or semi-supine state, vital signs were recorded before two cannulas were inserted, one in the hand or forearm to be used for venous sampling, with the hand heated to $55^{\circ} \mathrm{C}$ throughout the clamp allowing arterialisation of the Novo Nordisk A/S, Denmark) on the left shoulder of the participants, equal to time 0. venous blood (21). The second cannula was inserted on the opposite arm situated in the cubital fossa to be used for a variable infusion of insulin [15 units of Humulin $\mathrm{S}$ in $49 \mathrm{~mL}$ saline and $1 \mathrm{~mL}$ of participants own blood] or glucose $(20 \%$ in saline). The infusion was initiated with a target blood glucose level of $5.5 \mathrm{mmol} / \mathrm{L}(100 \mathrm{mg} / \mathrm{dL})$ $\pm 20 \%$ for $30-60$ min prior to the participant being relocated to the environmental chamber where baseline glucose levels were taken followed by the injection of insulin lispro (NovoFine 32G Tip etw 0.23/0.25 x $6 \mathrm{~mm}$,

In the environmental chamber, subjects were allowed to wear light clothes to mimic real life situations. The variable glucose infusion was used to maintain the target blood glucose level of $5.5 \mathrm{mmol} / \mathrm{L}(100 \mathrm{mg} / \mathrm{dL}) \pm 20 \%$ guided by an algorithm (22) and the participants' measured blood glucose concentration in the preceding 5 min. The blood glucose concentrations were measured by a glucose analyser (HemoCue ${ }^{\circledR}$ glucose 201+) and 
29 recorded together with the glucose infusion rate every 5-10 min throughout the clamp. Upon completion of the 30 clamp procedure, vital signs were checked and lunch was provided before discharge.

\section{Biochemical analysis}

32 Venous blood samples were collected at Visit 1 as part of screening procedures. Plasma blood samples were 33 centrifuged at $3,500 \times \mathrm{G}$ for $15 \mathrm{~min}$ at $5^{\circ} \mathrm{C}$ and analysed for $\mathrm{HbA} 1 \mathrm{c}$ on a Menarini Diagnostics $\mathrm{HB} 9210$ premier 34 (A.Menarini Diagnostics Ltd., Winnersh-Wokingham, UK).

\section{Statistical analysis}

36 The exogenous glucose infusion rate (GIR) was analysed every 5 to 10 minutes throughout the clamp. A 37 weighted local regression technique (LOESS) with a smoothing factor (SF) of 0.1 for the calculation of time38 related parameters and maximum GIR in accordance with previous studies that had investigated the 39 pharmacodynamics of short-acting insulin (23). The pharmacodynamic endpoints calculated for each clamp 40 study visit (Visit $2 b, 3$ and 4 ) were the maximum glucose infusion rate $\left(\mathrm{GIR}_{\max }\right)$ and time to maximum glucose 41 infusion rate $\left(t_{\text {GIRmax }}\right)$. In addition to total area under the curve (AUC) for GIR from 0 to 6 hours min $42\left(\mathrm{AUC}_{\mathrm{GIR} .0-6 \mathrm{~h}}\right)$, partial AUCs from 0-1 hour, 0-2 hours $\left(\mathrm{AUC}_{\mathrm{GIR} .0-1 \mathrm{~h}}\right), 0-6$ hours $\left(\mathrm{AUC}_{\mathrm{GIR} .0-2 \mathrm{~h}}\right)$ and 2-6 hours $43\left(\mathrm{AUC}_{\mathrm{GIR} .2-6 \mathrm{~h}}\right)$ following the insulin injection were also calculated to determine early and late insulin action. A 44 two-way ANOVA with temperature, humidity and their interaction as fixed effects and the subject as random 45 effect was used for $\mathrm{AUC}_{\mathrm{GIR} .0-1 \mathrm{~h}}, \mathrm{AUC}_{\mathrm{GIR} .0-2 \mathrm{~h}}, \mathrm{AUC}_{\mathrm{GIR} .0-6 \mathrm{~h}}, \mathrm{AUC}_{\mathrm{GIR} .2-6 \mathrm{~h}}, \mathrm{GIR}_{\max (\mathrm{SF}=0.1)}$ and $\mathrm{t}_{\mathrm{GIR} . \max (\mathrm{SF}=0.1) \text {. Data are }}$ 46 presented as mean (1SD) and statistical significance was set at $p \leq 0.05$. For graphical presentation (Figure 1) a 47 SF of 0.3 was used and 10 data points with GIR-values of nearly $40 \mathrm{mg} / \mathrm{kg} / \mathrm{min}$ in one subject were excluded in 48 order to minimise random GIR-fluctuations. Statistical analysis was conducted using SAS, version 9.4.

\section{Results}

50 The demographic and clinical characteristics of the adults with type 1 diabetes mellitus at baseline are presented 51 in Table 1.

\section{The independent effects of ambient temperature}


53 As illustrated in Figure 1 and Table 2, at temperature $30^{\circ} \mathrm{C}$ and humidity $10 \%$ the time-action curve of insulin 54 was shifted to the right, with a later $t_{\text {GIR.max }}(p=0.049)$ and a significantly greater $\operatorname{GIR}_{\max }(p=0.04)$, compared to 55 the condition at $15^{\circ} \mathrm{C}$ temperature and same level of humidity $(10 \%)$. Although $\mathrm{AUC}_{\mathrm{GIR} .0-1 \mathrm{~h},} \mathrm{AUC}_{\mathrm{GIR.0-2h}}$ and $56 \mathrm{AUC}_{\mathrm{GIR} .0-6 \mathrm{~h}}$ did not differ significantly between the conditions with different temperatures, there was a trend 10

\section{The independent effects of relative humidity}

There was no effect of humidity on insulin pharmacodynamics, as indicated by no significant differences in $\mathrm{GIR}_{\max }, \mathrm{t}_{\mathrm{GIR} \cdot \max }$ and $\mathrm{AUCs}$ for the time-action profile between the condition at temperature $30^{\circ} \mathrm{C}$ and humidity $10 \%$ vs. the condition at temperature $30^{\circ} \mathrm{C}$ and humidity $60 \%$ ( $p$ values between 0.21 and 0.95 ) (Table 2).

\section{The combined effects of ambient temperature and relative humidity}

When exploring the combined effects of temperature and humidity, $\mathrm{t}_{\mathrm{GIR} \cdot \max }(\mathrm{SF}=0.1)(p=0.008)$ occurred on average 44 min earlier $\left(\mathrm{AUC}_{\mathrm{GIR} .2-6 \mathrm{~h}}, p=0.017\right)$ at temperature $15^{\circ} \mathrm{C}$ and humidity $10 \%$ compared to temperature $30^{\circ} \mathrm{C}$ and humidity $60 \%$ (Figure 1, Table 2 ) with less glucose that needed to be infused at lower temperature and humidity, but no differences were seen for early $\left(\mathrm{AUC}_{\mathrm{GIR} .0-1 \mathrm{~h},} p=0.48, \mathrm{AUC}_{\mathrm{GIR} .0-2 \mathrm{~h},} p=0.87\right)$ and overall

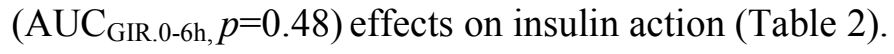

\section{Discussion}

By using the glucose clamp technique, the present study demonstrated that sudden changes in environmental conditions affect short-acting insulin analogue (insulin lispro) pharmacodynamics in adult men with type 1 diabetes mellitus. In response to higher temperature $\left(30^{\circ} \mathrm{C} v s .15^{\circ} \mathrm{C}\right)$ under fixed humidity there was a greater $\mathrm{GIR}_{\max }$ and a trend towards a greater $\mathrm{AUC}_{\mathrm{GIR} 2-6 \mathrm{~h}}$. High humidity affected insulin pharmacodynamics only when it was combined with high temperature. The mean time to $\mathrm{GIR}_{\max }$ was prolonged under $30^{\circ} \mathrm{C}$ temperature and 10 or $60 \%$ humidity compared to $15^{\circ} \mathrm{C}$ and $10 \%$ humidity and the $\mathrm{GIR}_{\max }$ and the late AUC (AUC $\mathrm{GIR}_{2}-6 \mathrm{~h}$ ) were greater, suggesting enhanced insulin absorption and peak effect. 
77 A limited number of studies have simulated the effects of environmental conditions on insulin 78 pharmacodynamics. Ronnemaa \& Koivisto investigated the acute effects of ambient temperature $\left(10^{\circ} \mathrm{C} v \mathrm{~s} .30^{\circ}\right.$ 79 C) with and without exercise on insulin absorption and postprandial glycaemia in patients with type 1 diabetes 80 mellitus, but in a different experimental protocol without using a glucose clamp. They showed no significant 10

regardless of exercise. We cannot provide comparative data on these aspects, given that our study is limited to insulin pharcodynamics rather than its pharmacokinetic profile. Furthermore, it is more challenging to detect differences in pharmacodynamic parameters than in pharmacokinetic parameters, as pharmacodynamic parameters are often characterised by greater variability and, therefore, the pharmacokinetic results would be expected to be in line with the pharmacodynamic findings in our study.

Exposure to higher temperatures compared to the high temperature $\left(30^{\circ} \mathrm{C}\right)$ investigated in this work has been shown to have favourable effects on time-action profiles of different types of insulin analogues. It is reported that sauna exposure (twice for $25 \mathrm{~min}$ at temperature $85^{\circ} \mathrm{C}$ and relative humidity $30-50 \%$ ) accelerated insulin absorption by $110 \%$ (assessed by measuring the disappearance rate of ${ }^{125}$ I-labelled rapid-acting insulin) compared with room temperature in 8 participants with diabetes (type 1 diabetes mellitus, $n=7$; type 2 diabetes mellitus, $n=1)(15)$. Hot baths (water temperature $\geq 40^{\circ} \mathrm{C}$ ) increased serum insulin levels 90 minutes after injection (14). Other studies have shown temperature effects on insulin pharmacodynamics, when heat is applied locally at the site of injection $(10-13,24)$. When a local heating device at the injection site $\left(\operatorname{InsuPatch}_{\mathrm{TM}}\right)$ was utilised to achieve skin temperature of $38.5^{\circ} \mathrm{C}$, the time to reach maximal action of a $0.2 \mathrm{U} / \mathrm{kg}$ bolus dose of insulin aspart decreased from $125 \mathrm{~min}$ to $90 \mathrm{~min}$ in adults with type 1 diabetes mellitus (13) and similarly at $40^{\circ} \mathrm{C}$ (12). Meal tolerance test studies showed that local heat resulted in significant reductions in the time to maximal insulin action and lower postprandial excursion in patients with type 1 diabetes mellitus $(11,24)$. 
04 These data suggest that high ambient temperature increases subcutaneous insulin absorption due to effects on 05 blood perfusion at the injection site. In line with these findings, we showed enhanced insulin action and a 06 prolonged time to maximum infusion rate with higher temperature compared to lower temperature. The latter 07 findings about the time to maximum infusion rate can be explained at least partially by a greater GIR $_{\max }$ 08 observed in the condition with the higher temperature (i.e., a greater $\mathrm{GIR}_{\max }$ is expected to be reached later). 09 The discrepancies between this and previous studies may be largely due to differences in the exposure to the 10 heat (i.e., extent, locality and duration). Although measurements of skin temperature were not available in this 11 study, these results are suggestive of a delayed thermoregulatory effect on subcutaneous tissue in the hotter 12 environment $\left(30^{\circ} \mathrm{C}\right)$, which may explain the absence of earlier changes in the environment surrounding the 13 insulin depot.

14 Conversely, we observed a shorter mean time to $\mathrm{GIR}_{\max }$ under $15^{\circ} \mathrm{C}$ and $10 \%$ humidity compared to $30^{\circ} \mathrm{C}$ 15 temperature and $10 \%$ humidity and a lower $\mathrm{GIR}_{\max }$ and late $\mathrm{AUC}\left(\mathrm{AUC}_{\mathrm{GIR} 2-6 \mathrm{~h}}\right)$. These results are in agreement 16 with a previous study by Vallerand et al. which showed that in response to an intravenous glucose tolerance test 17 under nude exposure to cold $\left(3 \mathrm{~h}\right.$ at $\left.10^{\circ} \mathrm{C}\right)$ plasma glucose area under the curve was lower and plasma glucose 18 levels returned to baseline levels within an hour compared to $2 \mathrm{~h}$ under warm exposure ( $3 \mathrm{~h}$ at $\left.29^{\circ} \mathrm{C}\right)$ despite low 19 insulin levels and enhanced carbohydrate metabolism (25). It is speculated that the marked effects of cold 20 exposure may due to enhanced insulin sensitivity and/or increased responsiveness for glucose uptake in 21 peripheral tissues such as skeletal muscles (25-27), although in the current study we cannot provide further 22 insight into these mechanisms, given that subcutaneous insulin was used and therefore, other factors (e.g., 43 visceral and subcutaneous tissues) may have differentially effect the pharmacodynamics parameters.

Short term exposure to different levels of relative humidity (10 and 60\%) under fixed temperature had no effect on the insulin time-action profile. However, exposure to high relative humidity in combination with high ambient temperature resulted in a prolonged time to $\mathrm{GIR}_{\max }$ and a greater insulin pharmacodynamic effect 27 compared to the responses to the low temperature low humidity condition, suggesting that high humidity may 28 augment the high temperature effect on enhanced insulin absorption from the injection site, but has little effect 29 in its own right. 
30 In conclusion, high ambient temperature resulted in greater insulin peak effect compared to low ambient

31 temperature, with the contribution of high relative humidity to insulin absorption only apparent at high ambient

32 temperature. This suggests that patients with type 1 diabetes mellitus entering environmental higher

33 temperatures with or without high humidity could experience more hypoglycaemic events.

\section{Acknowledgements}

36 We thank all study participants for their commitment to this study. This study was supported by Hull and East

37 Yorkshire Hospitals Charitable Funds. No potential conflict of interest relevant to this article was reported.

\section{Authors' contributions}

40 AA, ZJ, TH, ASR, ATG, DH, ESK, SLA and TS participated in study conception and design. AA performed

41 the acquisition of data. AA, MP, TH, ASR, SLA and TS participated in analysis and/or interpretation of data.

42 MP drafted the first draft of the paper; all authors reviewed and approved the final manuscript. TS is the 43 guarantor of the study. 
44 References

45 1. Heinemann L. Variability of insulin absorption and insulin action. Diabetes Technol Ther. 2002;4(5):673-82.

462 2. Freckmann G, Pleus S, Haug C, Bitton G, Nagar R. Increasing local blood flow by warming the application site:

47 beneficial effects on postprandial glycemic excursions. J Diabetes Sci Technol. 2012;6(4):780-5.

48 3. Sohmiya M, Kanazawa I, Kato Y. Seasonal changes in body composition and blood HbA1c levels without weight

49 change in male patients with type 2 diabetes treated with insulin. Diabetes Care. 2004;27(5):1238-9.

50 4. Ishii H, Suzuki H, Baba T, Nakamura K, Watanabe T. Seasonal variation of glycemic control in type 2 diabetic

51 patients. Diabetes Care. 2001;24(8):1503-.

5. Tsujimoto T, Yamamoto-Honda R, Kajio H, Kishimoto M, Noto H, Hachiya R, et al. Seasonal Variations of Severe Hypoglycemia in Patients With Type 1 Diabetes Mellitus, Type 2 Diabetes Mellitus, and Non-diabetes Mellitus. Medicine. 2014;93(23).

6. Vazeou AG, Kordonouri O, Witsch M, Hermann JM, Forsander G, de Beaufort C, et al. Seasonality at the clinical onset of type 1 diabetes-Lessons from the SWEET database. Pediatr Diabetes. 2016;17:32-7.

7. Ronnemaa T, Koivisto VA. Combined effect of exercise and ambient temperature on insulin absorption and postprandial glycemia in type I patients. Diabetes Care. 1988;11(10):769-73.

8. Berglund L, Berne C, Svardsudd K, Garmo H, Melhus H, Zethelius B. Seasonal variations of insulin sensitivity from a euglycemic insulin clamp in elderly men. Ups J Med Sci. 2012;117(1):35-40.

9. Dillon RS. Improved serum insulin profiles in diabetic individuals who massaged their insulin injection sites. Diabetes Care. 1983;6(4):399-401.

10. Landau Z, Feldman D, Shusterman A, Wainstein J, Klonoff D, Nyberg I, et al. Improved pharmacokinetic and pharmacodynamic profile of insulin analogues using InsuPatch, a local heating device. Diabetologia. 2012;55:S54-S. 11. Raz I, Weiss R, Yegorchikov Y, Bitton G, Nagar R, Pesach B. Effect of a local heating device on insulin and glucose pharmacokinetic profiles in an open-label, randomized, two-period, one-way crossover study in patients with type 1 diabetes using continuous subcutaneous insulin infusion. Clin Ther. 2009;31(5):980-7.

12. Cengiz E, Weinzimer SA, Sherr JL, Tichy EM, Carria L, Cappiello D, et al. Faster in and faster out: accelerating insulin absorption and action by insulin infusion site warming. Diabetes Technol Ther. 2014;16(1):20-5.

13. Cengiz E, Weinzimer SA, Sherr JL, Tichy E, Martin M, Carria L, et al. Acceleration of insulin pharmacodynamic profile by a novel insulin infusion site warming device. Pediatr Diabetes. 2013;14(3):168-73.

14. Berger M, Cuppers HJ, Hegner H, Jorgens V, Berchtold P. Absorption Kinetics and Biologic Effects of Subcutaneously Injected Insulin Preparations. Diabetes Care. 1982;5(2):77-91.

15. Koivisto VA. Sauna-Induced Acceleration in Insulin Absorption from Subcutaneous Injection Site. Brit Med J. 1980;280(6229):1411-3.

16. Tyrovolas S, Chalkias C, Morena M, Kalogeropoulos K, Tsakountakis N, Zeimbekis A, et al. High relative environmental humidity is associated with diabetes among elders living in Mediterranean islands. J Diabetes Metab Disord. 2014;13(1):25.

79 17. Sharma VM, Pichan G, Panwar MR. Differential effects of hot-humid and hot-dry environments on mental 80 functions. Int Arch Occup Environ Health. 1983;52(4):315-27.

81 18. Petrofsky J, Berk L, Alshammari F, Lee H, Hamdan A, Yim JE, et al. The effect of moist air on skin blood flow 82 and temperature in subjects with and without diabetes. Diabetes Technol Ther. 2012;14(2):105-16. 
83 19. Lim CL, Byrne C, Lee JK. Human thermoregulation and measurement of body temperature in exercise and 84 clinical settings. Ann Acad Med Singapore. 2008;37(4):347-53.

85 20. Epstein Y, Roberts WO. The pathopysiology of heat stroke: an integrative view of the final common pathway. 86 Scand J Med Sci Sports. 2011;21(6):742-8.

87 21. Abumrad NN, Rabin D, Diamond MP, Lacy WW. Use of a heated superficial hand vein as an alternative site for 88 the measurement of amino acid concentrations and for the study of glucose and alanine kinetics in man. Metabolism. 89 1981;30(9):936-40.

90 22. DeFronzo RA, Tobin JD, Andres R. Glucose clamp technique: a method for quantifying insulin secretion and 91 resistance. Am J Physiol. 1979;237(3):E214-23.

92 23. de la Pena A, Seger M, Soon D, Scott AJ, Reddy SR, Dobbins MA, et al. Bioequivalence and comparative 93 pharmacodynamics of insulin lispro $200 \mathrm{U} / \mathrm{mL}$ relative to insulin lispro (Humalog(R)) $100 \mathrm{U} / \mathrm{mL}$. Clin Pharmacol Drug 94 Dev. 2016;5(1):69-75.

95 24. Freckmann G, Pleus S, Westhoff A, Krinelke LG, Buhr A, Jendrike N, et al. Clinical performance of a device that 96 applies local heat to the insulin infusion site: a crossover study. J Diabetes Sci Technol. 2012;6(2):320-7.

97 25. Vallerand AL, Frim J, Kavanagh MF. Plasma-Glucose and Insulin Responses to Oral and Intravenous Glucose in 98 Cold-Exposed Humans. J Appl Physiol. 1988;65(6):2395-9.

99 26. Vallerand AL, Zamecnik J, Jacobs I. Plasma-Glucose Turnover during Cold Stress in Humans. J Appl Physiol. 00 1995;78(4):1296-302.

01 27. Hanssen MJW, Hoeks J, Brans B, van der Lans AAJJ, Schaart G, van den Driessche JJ, et al. Short-term cold 02 acclimation improves insulin sensitivity in patients with type 2 diabetes mellitus. Nat Med. 2015;21(8):863-5. 


\section{$04 \quad$ Figure Legends}

05 Figure 1. Average glucose infusion rate (GIR) $(\mathrm{mg} / \mathrm{kg} / \mathrm{min})$ values to maintain euglycaemia under different 06 environmental conditions; T15/H10: temperature $15^{\circ} \mathrm{C}$ and humidity $10 \%, \mathrm{~T} 30 / \mathrm{H} 10$ : temperature $30^{\circ} \mathrm{C}$ and 07 humidity $10 \%$ and $\mathrm{T} 30 / \mathrm{H} 60$ : temperature $30^{\circ} \mathrm{C}$ and humidity $60 \%$. 
08 Table 1: Baseline characteristics of the participants $(n=10)$.

\begin{tabular}{|l|l|}
\hline & Adults with Type 1 diabetes (n=10) \\
\hline Age (years) & $28.3 \pm 7.1$ \\
\hline Weight (kg) & $74.1 \pm 12$ \\
\hline Height (cm) & $170.6 \pm 5.7$ \\
\hline BMI (kg/m ${ }^{\mathbf{2}}$ ) & $24.3 \pm 2.9$ \\
\hline Systolic BP (mmHg) & $124.2 \pm 9.4$ \\
\hline Diastolic BP (mmHg) & $75.6 \pm 7.5$ \\
\hline Duration of diabetes (years) & $18.8 \pm 7.7$ \\
\hline HbA1c (\%) & $7.9 \pm 0.8$ \\
\hline HbA1c (mmol/mol) & $63 \pm 6.7$ \\
\hline
\end{tabular}

09 Data are presented as means $\pm 1 \mathrm{SD}$. BMI body mass index, BP blood pressure, HDL high density lipoprotein, 10 LDL low density lipoprotein, HbA1C Haemoglobin A1c. 
Table 2: $\mathrm{AUC}_{\mathrm{GIR}}$ for $0-1 \mathrm{~h}, 0-2 \mathrm{~h}, 0-6 \mathrm{~h}$ and $2-6 \mathrm{~h}, \mathrm{GIR}_{\max }$ and $\mathrm{t}_{\mathrm{GIR} . \max }$

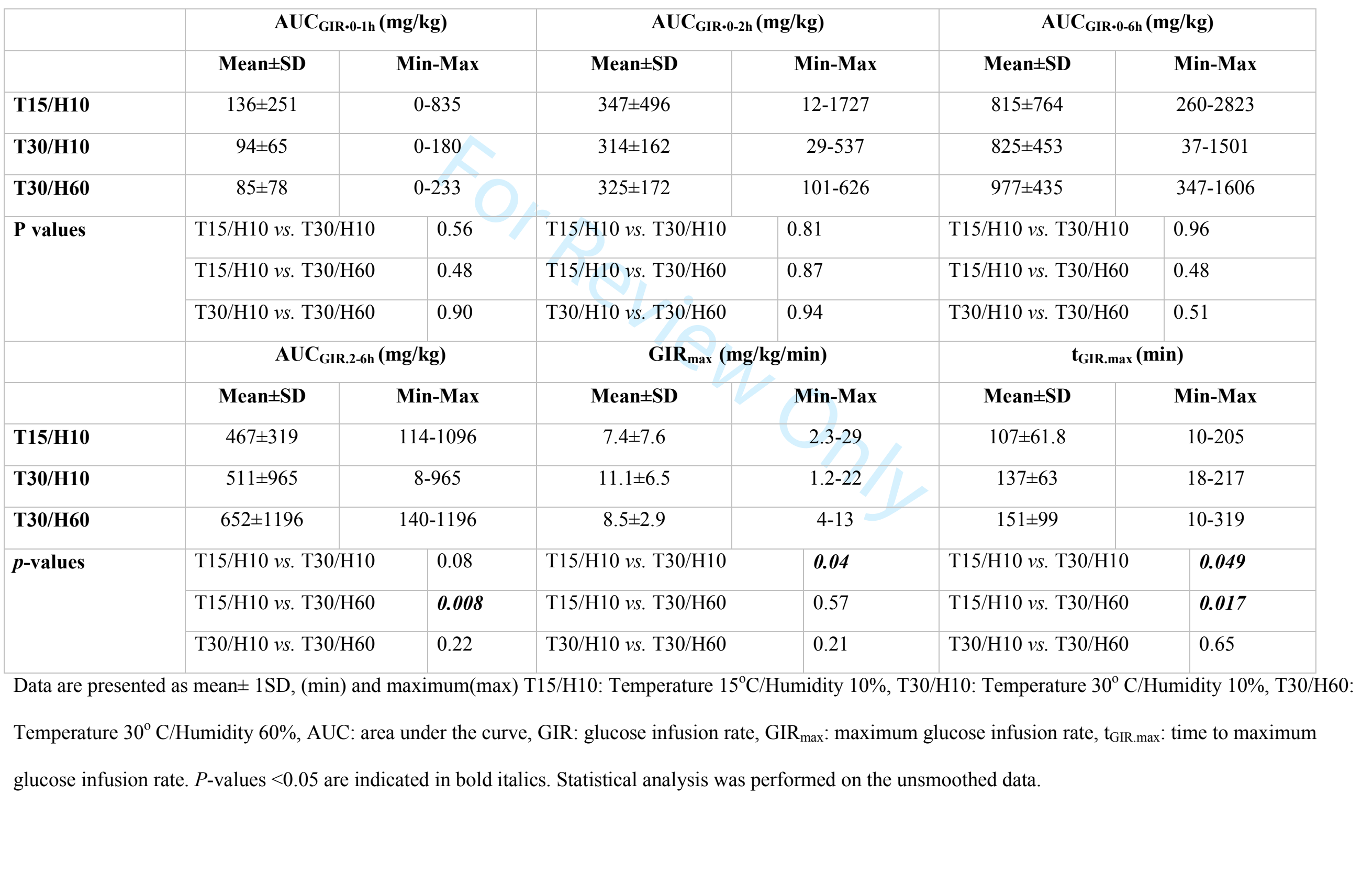


Page 17 of 17

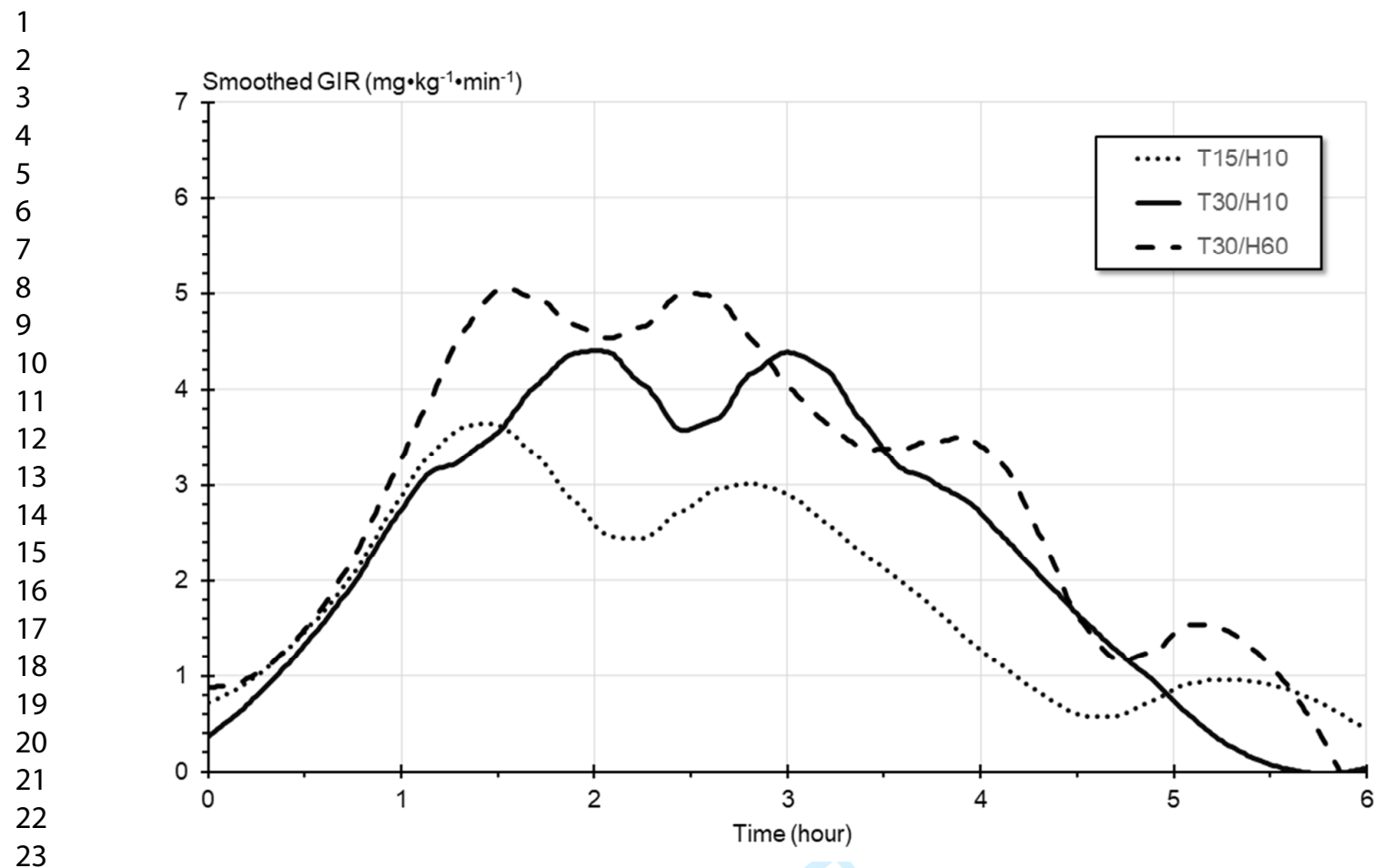

Figure 1. 